CASE STUDY

\title{
Our Quest for Success: Using a Multidisciplinary Students-as-Partners Model to Develop an Innovative Online Learning Game
}

\author{
Meredith G.H. Burling ${ }^{a}$, Lina Rahouma ${ }^{a}$, Arla Good ${ }^{a}$, Joleine C. Kaspera , Samantha Kranyak ${ }^{a}$, \\ Kieran Ramnarine ${ }^{a}, \&$ * Kosha Bramesfeld ${ }^{\text {ab }}$

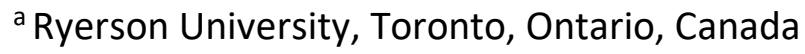 \\ ${ }^{b}$ University of Toronto Scarborough, Toronto, Ontario, Canada \\ Contact: kosha.bramesfeld@utoronto.ca
}

\begin{abstract}
In their review of the students-as-partners literature, Mercer-Mapstone et al. (2017) found that only 5-6\% of published research articles on student-partnership models focused on multidisciplinary partnerships. This case study, authored by five undergraduate students and two academics, sought to examine the utility of using a multidisciplinary students-as-partners approach to advance the development of an online learning game focused on food insecurity. The multidisciplinary nature of the partnership facilitated perceptions of an equitable partnership, contributed to innovative design ideas, and conferred several benefits to the collaborators beyond those traditionally seen in the students-as-partners literature (Mercer-Mapstone et al., 2017). However, the multidisciplinary nature of the partnership also posed unique mentoring and coordination challenges that should be considered when adopting a multidisciplinary approach to teaching innovation.
\end{abstract}

KEYWORDS

students-as-partners, game-based learning, food security, multidisciplinary

\section{PROJECT OVERVIEW}

In their review of the students-as-partners literature, Mercer-Mapstone et al. (2017) found that only 5-6\% of published research articles focused on multidisciplinary partnerships. As such, there is a need to examine the unique advantages and challenges of adopting a multidisciplinary approach to students-as-partners. The development of an online learning game offers an ideal environment for doing so. Digital learning games have grown in popularity as a teaching tool to engage students in the learning process (Arnab et al., 2015); but their development requires expertise across multiple domains, including computer programming, art

\section{CC-BY Licence 4.0 This is an Open Access article distributed under the terms of the Creative Commons - Attribution License 4.0 International (https://creativecommons.org/licenses/by/4.0/), which permits unrestricted use, distribution, and reproduction in any medium, provided the original work is properly attributed.}


design, and user experience. Most educators do not have the skills needed to create digital learning games on their own (Gunter, Kenny, \& Vick, 2008). We suggest that a students-aspartners model offers a unique opportunity to bring together student expertise from a variety of disciplines in order to co-design these games. We also argue that these multidisciplinary partnerships offer students and academic staff important opportunities for cross-disciplinary learning and professional development, above and beyond single-discipline partnerships.

A students-as-partners approach includes students in the co-creation of teaching and learning via "a collaborative, reciprocal process through which all participants have the opportunity to contribute equally, although not necessarily in the same ways, to curricular or pedagogical conceptualization, decision-making, implementation, investigation, or analysis" (Cook-Sather, Bovill, \& Felten, 2014, p. 6-7). In these partnerships students are valued as the individuals who are closest to the learning process, and therefore, best able to provide expertise on what it is like to a be a learner (Cook-Sather et al., 2014; Woolmer et al., 2016). Students are rarely thought of as subject-matter experts within these partnerships, however. Indeed, students' lack of subject-matter expertise is cited as a concern that faculty and students share about these partnerships (Bovill, Cook-Sather, Felton, Millard, and Moore-Cherry, 2016).

In this paper we challenge this view of expertise and suggest that students do have a place in providing unique subject-matter expertise, separate from that of faculty, especially within the context of multidisciplinary approaches to teaching innovation (Woolmer et al., 2016). Specifically, we discuss a case study in which we drew on student subject-matter expertise across multiple disciplines to co-design an innovative online learning game. In the process, we used the multidisciplinary nature of the partnership as a tool for stripping away the expert-based power differentials that typically exist between faculty and students. In its place, we created a partnership model that emphasized student expertise, shared goals, collaborative responsibility, and reciprocal learning (see Mathews, Dwyer, Hine, and Turner, 2018).

\section{PROJECT BACKGROUND}

The FSQ Project was a multidisciplinary effort between three academics and eight students who worked together to design a learning game focused on food insecurity. The project was initiated when $A M$, an instructor of nutrition, approached $K B$, an instructor of psychology, about the possibility of working together to design a learning game focused on food insecurity. KB and her colleague, AG, a post doctorate in psychology, had previously used student consultant models to design and evaluate two in-class learning games (Bramesfeld \& Good, 2015; 2016). They had not previously developed a digital learning game, however. Fortunately, two important resources came together to make the project possible. First, we secured an eCampusOntario grant that provided funds to hire a student leadership team to design and develop the game. Second, our team was accepted into a pilot project for a new Library Collaboratory initiative that provided us with the use of a shared innovation space and connected us with eLearning and technology experts. AM helped launch the learning game project as a subject matter expert, while $\mathrm{KB}^{*}$ and $\mathrm{AG}^{*}$ worked in collaboration with student partners to co-design the game (*indicates an author on this paper). 
As the need for various game development roles were identified, funds from the grant were used to hire student leaders from a variety of disciplines across the university (e.g., nutrition, computer science, communication, digital media). Once hired, students were given freedom to shape their own job titles and job descriptions. Our final team included the following student leadership roles: Aboriginal Experiences Research Assistant (JK*), Game Developer $\left(\mathrm{KR}^{*}\right)$, Food Security Storytelling Consultant $\left(\mathrm{LR}^{*}\right)$, Food Security Research Assistant (JB), Indigenous Resource Trainee (TM), Creative Assets Developer (MB*), Concept Artist and Storyteller (SK*), and Technology Consultant (MF).

Each student leader was involved with the project for a total of 6 to 12 months. Consistent with Bovill et al.'s (2016) description of students as pedagogical co-designers, student leaders shared responsibility for planning, designing, developing, and evaluating the learning game. Like other students-as-partners projects, students on the team were treated as the experts most closely oriented to the experience of being a learner (Cook-Sather et al., 2014; Woolmer et al., 2016). Students were also treated as subject-matter experts within their own disciplinary domains. All members of the team were provided with access to the Collaboratory innovation space. Our team met regularly to provide updates, exchange ideas, and perform collaborative work. Our team also consulted with 9 subject matter experts, 3 nutrition students, and 15 instructional design and technology experts. A link to the game, as well as a description of our team members, partners, and game development process are provided on our project website (https://www.ryerson.ca/openlearning/projects/food-security-quest/).

\section{PROJECT EVALUATION AND OUTCOMES}

To evaluate the success of our partnership, the seven authors of this paper worked together to identify a series of self-reflection questions focused on (a) the nature of our partnership, (b) the distribution of decision making power, the (c) strengths and (d) limitations of our partnership, and (e) the uniqueness of our partnership relative to other class-based and/or research-based experiences. (Later, in response to a reviewer's comment, we returned to the question of uniqueness to additionally explore how our project differed in relation to other work-integrated experiences). Each author provided written responses to these questions. Five authors then analyzed the responses to identify key themes. This analysis revealed that our multidisciplinary partnership was defined by a sense of equity and shared responsibility that created a powerful sense of authenticity and opportunity for professional development, but also created anxiety and difficulty coordinating action. Our team meetings and partnership with the Collaboratory were key for overcoming these challenges.

\section{Equity}

Students on our team noted that a defining feature of our partnership was the equity between the students and staff. Students acknowledged that a hierarchy continued to exist between faculty and students, but it never felt like it had an impact on any of the work that was performed throughout the partnership. Everyone was respected and taken seriously, which allowed for increased levels of creativity and collaboration between the members of the team. Students also liked choosing their own job titles, which reinforced their place as equal co- 
designers on the project. In their responses to the feedback questions, the language that students used to describe their roles in the project included terms such as "respected", "trusted", "empowered", "valued", "equally important ", "encouraged", "included", and "supported". One student author noted, "I have never experienced a group that genuinely made every group member feel equal and valued".

Similarly, the faculty viewed the students as truly equal partners. Because each individual on the team held expertise that was crucial to the task, the faculty were stripped of their traditional role as the "expert in the room". This changed the normal power dynamics, which created an authentic environment for true collaboration.

\section{Shared Responsibility}

The high level of autonomy, leadership, and flexibility given to the students created a powerful sense of shared responsibility and joint ownership of the project. This created meaningful opportunities for professional development and growth (as discussed in the next section); however, it also created significant anxieties for members of our team.

Students described their initial feelings about the level of responsibility as "daunting", "too much", "imbalanced towards the students", and "overwhelming". Students expressed wanting to rely on the faculty for mentorship, but being unable to do so as the faculty members were not content experts within their domain. The project forced students to go beyond their comfort zones to become self-reliant and to seek out their own sources of support. Despite these anxieties, students also noted how empowering it was to meet these challenges:

At first, I felt that I was given too much creative power. I was not used to having to make decisions on my own. I later enjoyed having creative control, and I felt proud that my team trusted me.

Faculty also reported a complex duality in which they held ultimate responsibility for the project from a budgetary and reporting standpoint, but wanted to respect the collaborative partnership and give students freedom and autonomy to be creative. The trade-off in granting students this freedom is that the faculty often felt disconnected from the development process. Moreover, due to the multidisciplinary nature of the team, the faculty found it challenging to coordinate and mentor students coming from disciplines other than their own.

\section{Professional Development}

Despite these challenges, team members were in agreement that the shared ownership of the project created opportunities for innovation, reciprocal learning, professional development, and growth. A common theme that emerged in our analysis is that our project felt more "real" to our team members than other research and class-based projects have felt. One student described it well,

It was different in the sense that I was applying concepts that I have learnt in the class to real life experiences... In very few other courses in my program or 
projects do I get the opportunity to reflect on my personal experiences and incorporating it in to a project, in that aspect it was definitely very different and unique than any course work I have done in the past.

The "realness" of our project occurred in large part due to our unique treatment of student expertise. Unlike most of the students' prior academic and research-based experiences, our partnership recognized students as equal partners in the contribution of subject-matter expertise. This focus on subject-matter expertise was reminiscent of students' other workintegrated experiences in practicums and co-ops, however, unlike these other work-integrated experiences, students also found themselves drawing on their expertise as students to advance the project. In their own words students noted,

[When developing the game] I thought about the "games" that I had to play as a student and I definitely used that experience to shape something together that was a richer experience.

Being an Indigenous student of nutrition, and having studied food security specifically, absolutely had an influence in how I thought/reacted about and to the game.

The duality between student and subject-matter expertise often created interesting tensions. For example, early on in our process we had a discussion about how to introduce the core instructional material of the game. From a student perspective, we were in agreement that this information should be "front and center", but from a game development perspective it was also clear that centering this material could potentially take away from the enjoyment of the game. Had we centered the student experience, our game might have been less engaging. Had we centered the subject matter expertise, the game might not have been as educational. However, combining the perspectives forced us to work through the tension to generate a solution designed to meet both the educational and entertainment goals of the project.

The opportunity to lend multiple forms of expertise to the project contributed greatly to students' opportunity to share reciprocal knowledge and skills with one another, while also developing a dynamic collective knowledge about the project.

We had to step out of our personal fields of expertise to understand new subject, contexts, and realities not previously understood coming from our separate backgrounds.

Working on the team was an incredible experience that has impacted me for the better personally, professionally and academically. I have a deeper respect and appreciation for "the process" and the importance of thorough planning... I learned how to be a better leader working with such a strong team who all brought admirable leadership qualities to the table.... 
The faculty also expressed an appreciation of the reciprocal learning experience. The multidisciplinary nature of the team contributed to the innovation of the project and afforded growth opportunities well beyond working within one discipline. Most surprising, however, was the extent to which this project pushed the faculty to develop their own leadership and professional development skills. Both KB and AG had previously managed research and teaching innovation projects with students from their own discipline. In previous contexts, their leadership value came from their expertise of their disciplinary knowledge. However, in the current project, the faculty could not rely on their own content expertise as a source of leadership, as they were not the content experts on this multidisciplinary team. As such, the faculty had to develop their skills in empowering, motivating, and guiding student leaders to find their own solutions. This process pushed all of us well outside of our comfort zones, but was also tremendously rewarding and growth promoting.

\section{Coordination}

In the words of Leopold (2006), it is "not easy to bring together the creative ideas of students from [] various backgrounds and to mediate between them" (p. 130). Likewise, our team found it difficult to understand the jargon, processes, and expectations of team members from other disciplines. Each of us had different ideas about the overall goals, direction, and structure of the project. Furthermore, some tasks did not lend themselves well to collaboration, as it was easier for a team member to finish the task on their own. At times this meant that our team felt less like a cohesive multidisciplinary group and more like individuals working in separate silos. Furthermore, members of our team were hired in a staggered process over several months, as we often didn't know what roles we needed until we needed them. Unfortunately this meant that some members of our team were brought on to the project after key decisions about the project had already been made. The students pointed out that this threatened the true equity of the partnership because not everybody had a voice in the process from the beginning. Working through these challenges added to our time pressures.

Despite these coordination difficulties, our team managed to pull it all together remarkably well. One student likened our process to a puzzle. Each of us contributed our own unique pieces to the puzzle, but in the end it all came together a whole. One factor that facilitated the success of our process was our regular team meetings. Team meetings allowed for the integration of ideas across disciplines and opportunities for sharing knowledge. Access to the shared Collaboratory space also contributed to our partnership. We found the shared space to be creative and fun. The space provided resources, including abundant white board space to brainstorm and record ideas, and access to technology experts with whom we could exchange ideas and ask questions. The Collaboratory also provided workshops and mentoring opportunities beyond our project, which contributed to the professional growth of our team and helped fulfill the mentoring vacuum mentioned earlier. Moreover, students on our team were given the same level of access to the shared innovation space as faculty, which created a neutral ground for students and faculty to come together in true collaboration. In the words of one student, the Collaboratory "made the team feel excited to be there". Our access to this 
collaborative physical space became a catalyst for creating the metaphorical space needed to create a genuine partnership (Dwyer, 2018).

\section{CONCLUSIONS AND RECOMMENDATIONS}

In conclusion, the multidisciplinary structure of our partnership turned out to be crucial for achieving our desired outcomes. Similar to other student-as-partners projects, our project benefited from the expertise that students could provide as the stakeholders closest to the learning process. Additionally, students' expertise as subject-matter experts enhanced the overall quality of our online learning game and created unique professional development opportunities. As a consequence, our partnership produced many of the same outcomes as other students-as-partners projects. Using the same language as used in Mercer-Mapstone et al.'s (2017) literature review (Tables 3 \& 4, pp. 11-12), our project promoted shared ownership of the learning process, increased understanding of "other's" experiences, enhanced trust between students and faculty, and promoted self-awareness and skill development for students. Importantly, however, the multidisciplinary nature of our partnership also promoted outcomes seen less commonly in the research literature, including positively shifted power dynamics between students and faculty, enhanced student-to-student relationships, improved learning outside of the discipline, enhanced career development for faculty, and opportunities for student-faculty co-authorship of a publication (via this paper).

Our multidisciplinary partnership also offered unique challenges. McKerlie et al. (2018) noted that collaborating with students on the development of digital learning tools takes time, as faculty and students often approach digital learning development with differing goals and expectations. Our experiences echoed this point. Our team found itself reconciling differences in perspective between student and faculty, as well as differences in perspective across discipline. This extra layer of difference added additional time pressures as it was often difficult to overcome process barriers that arose due to differing disciplinary knowledge, jargon, and expectations.

As novices to the digital game development process, our faculty team also struggled to know in advance which student leadership roles would be needed to complete the project. Students on our team noted that the staggered hiring of the student leadership roles threatened the equity of the partnership, as students who were hired later in the process felt locked out of key decisions made at the beginning of the project. This challenge highlights a key difference between our multidisciplinary partnership and other multidisciplinary partnerships, such as the one described by Woolmer et al. (2016). In Woolmer et al.'s partnership, team members came from different disciplines, but there were faculty and students from each discipline on the project. Thus faculty could anticipate and "front load" the planning work of the project to ensure clear roles and expectations. In contrast, the faculty on our team came from very different disciplines than the students on our team. This reality made it very difficult for our faculty team to anticipate and plan our work in advance. Our observation suggests that there may be a steeper learning curve involved in effectively planning for partnerships in which students and faculty come from different disciplines. 
Relatedly, the multidisciplinary nature of the project also created challenges when it came to providing student mentorship and guidance. A strength of our partnership is that shifting the expectation of disciplinary expertise on to the students helped to reduce traditional faculty-student power dynamics predicated on disciplinary expertise. Given this, we are wary of addressing this mentorship gap by adding in more faculty collaborators, as this could reposition expertise - and the power that comes with it - back into the hands of faculty. A better model might involve the inclusion of a secondary mentorship model in which student leaders are asked to work with external mentors from their own discipline who can act as subject matter guides as needed, but who maintain an arms-length distance from the project so as to ensure that students remain the primary subject matter expert for the team (see Woolmer et al., 2016 for a similar mentoring framework). We partially achieved this model via the Collaboratory technology advisory group who provided general advice and mentoring to our students. Moving forward, we aim to formalize these connections more clearly to ensure that each student has a designated mentor within their own discipline to whom they can turn to for advice.

Finally, our project would not have been a success without the eCampusOntario funding and our partnership with the Collaboratory. Mercer-Mapstone et al. (2017) and others have pointed out that students-as-partners models are most successful at empowering co-creation when these programs can be "scaled up" to create opportunities for all students. Institutional programs such as the Library Collaboratory may provide an important framework for scaling up innovation projects such as ours as they create efficiencies in providing innovation space and resources to faculty and students from multiple disciplines who wish to work in partnership.

\section{NOTE ON CONTRIBUTORS}

Meredith G.H. Burling and Lina Rahouma (listed alphabetically) are the lead student authors on the paper. They were instrumental in (a) identifying the question prompts that were sent out to our authorship team, (b) analyzing the responses in order to identify the key themes, (c) finding articles that helped contextualize the themes within the broader SaP literature, and (d) outlining an initial draft of the manuscript. They also summarized the reflections about the partnership from a student perspective.

Arla Good, Joleine C. Kasper, Samantha Kranyak, and Kieran Ramnarine (listed alphabetically) are supporting authors on the paper. They contributed to the development of the question prompts, provided reflections about the partnership, contributed to the identification of paper themes, and provided feedback on a draft of the paper. Arla lent voice to the faculty perspective, whereas Joleine, Samantha, and Kieran lent voice to the student perspective.

Kosha D. Bramesfeld (corresponding author) is the faculty lead and corresponding author for the paper. Along with Arla, she provided reflections about the faculty side of the partnership. She also contributed to the development of the question prompts, the identification of paper themes, and provided mentorship and writing guidance during the development of the paper. She was affiliated with Ryerson University during the development of the Food Security Quest 
project, but authored this paper after becoming affiliated with the University of Toronto Scarborough.

\section{ACKNOWLEDGEMENTS}

The development and evaluation of the Food Security Quest (FSQ) was supported by a 2016-2018 Research and Innovation grant through eCampusOntario. The Food Security Quest was also part of a 2017-2018 pilot project with the Ryerson University Library Collaboratory. We would like to thank the other members of the FSQ team, without whom our team would not be compete: Dr. Andrea Moraes, Tim Mt. Pleasant, Marissa Frosst, and Jennifer Biewald. It was great working with you on the FSQ project!

\section{Disclosure statement}

No potential conflicts of interest were reported by the authors.

\section{REFERENCES}

Arnab, S., Lim, T., Carvalho, M. B., Bellotti, F., Freitas, S., Louchart, S., Suttie, N., Berta, R., \& De Gloria, A. (2015). Mapping learning and game mechanics for serious games analysis. British Journal of Educational Technology, 46, 391-411. https://doi.org/10.1111/bjet.12113

Bovill, C., Cook-Sather, A., Felten, P., Millard, L., \& Moore-Cherry, N. (2016). Addressing potential challenges in co-creating learning and teaching: overcoming resistance, navigating institutional norms and ensuring inclusivity in student-staff partnerships. Higher Education, 71, 195-208. https://doi.org/10.1007/s10734-015-9896-4

Bramesfeld, K. D. \& Good, A. (2016). C'est La Vie! The Game of Social Life: Using an intersectionality approach to teach about privilege and structural inequality. Teaching of Psychology, 43, 294-304. http://dx.doi.org/10.1177/0098628316662758

Bramesfeld, K. D., \& Good, A. (2015). The Game of Social Life: An assessment of a multidimensional poverty simulation. Teaching Sociology, 43, 92-103. http://dx.doi.org/10.1177/0092055X15569316

Cook-Sather, A., Bovill, C., \& Felten, P. (2014). Engaging students as partners in teaching and learning. San Francisco, CA: Jossey-Bass.

Dwyer, A. (2018). Toward the formation of genuine partnership spaces. International Journal for Students as Partners, 2(1). https://doi.org/10.15173/iisap.v2i1.3503

Gunter, G., Kenny, R., \& Vick, E. (2008). Taking educational games seriously: Using the RETAIN model to design endogenous fantasy into standalone educational games. Educational Technology Research and Development, 56(5-6), 511-537. https://doi.org/10.1007/s11423-007-9073-2

Leopold, C. (2006). Sound-Sights An Interdisciplinary Project. Nexus Network Journal, 8(1), 123131. https://doi.org/10.1007/s00004-006-0012-z 
Matthews, K. E., Dwyer, A., Hine, L., \& Turner, J. (2018). Conceptions of students as partners. Higher Education, 76, 957-971. https://doi.org/10.1007/s10734-018-0257-y

McKerlie, R., Rennie, E., Hudda, S., McAllan, W., Al-Ani, Z., McLean, W., \& Bagg, J. (2018). Facilitation of student-staff partnership in development of digital learning tools through a special study module. International Journal for Students as Partners, 2(1). https://doi.org/10.15173/ijsap.v2i1.3235

Mercer-Mapstone, L., Dvorakova, S. L., Matthews, K. E., Abbot, S., Cheng, B., Felten, P., ... \& Swaim, K. (2017). A systematic literature review of students as partners in higher education. International Journal for Students as Partners, 1(1). Retrieved from https://doi.org/10.15173/ijsap.v1i1.3119

Woolmer, C., Sneddon, P., Curry, G., Hill, B., Fehertavi, S., Longbone, C., \& Wallace, K. (2016). Student staff partnership to create an interdisciplinary science skills course in a research intensive university, International Journal for Academic Development, 21:1, 16-27, https://doi.org/10.1080/1360144X.2015.1113969 